\title{
- Perspectives •
}

\section{The Chinese Carbon-Neutral Goal: Challenges and Prospects $*$}

\author{
Ning ZENG ${ }^{* 1,2}$, Kejun JIANG ${ }^{3}$, Pengfei HAN ${ }^{4,2}$, Zeke HAUSFATHER ${ }^{5}$, Junji CAO*6, \\ Daniel KIRK-DAVIDOFF ${ }^{1}$, Shaukat ALI ${ }^{7}$, and Sheng ZHOU ${ }^{8}$ \\ ${ }^{1}$ Department of Atmospheric and Oceanic Science, and Earth System Science Interdisciplinary Center, \\ University of Maryland, College Park 20742, Maryland, USA \\ ${ }^{2}$ State Key Laboratory of Numerical Modeling for Atmospheric Sciences and Geophysical Fluid Dynamics, \\ Institute of Atmospheric Physics, Chinese Academy of Sciences, Beijing 100029, China \\ ${ }^{3}$ Energy Research Institute, National Development and Reform Commission, Beijing 100045, China \\ ${ }^{4}$ Carbon Neutrality Research Center, Institute of Atmospheric Physics, Chinese Academy of Sciences, \\ Beijing 100029, China \\ ${ }^{5}$ Breakthrough Institute, Oakland 94612, California, USA \\ ${ }^{6}$ Institute of Atmospheric Physics, Chinese Academy of Sciences, Beijing 100029, China \\ ${ }^{7}$ Global Change Impact Study Centre, Ministry of Climate Change, Islamabad 45250, Pakistan \\ ${ }^{8}$ Institute of Energy, Environment and Economy, Tsinghua University, Beijing 100084, China
}

(Received 10 August 2021; revised 13 December 2021; accepted 21 December 2021)

\begin{abstract}
On 22 September 2020, within the backdrop of the COVID-19 global pandemic, China announced its climate goal for peak carbon emissions before 2030 and to reach carbon neutrality before 2060. This carbon-neutral goal is generally considered to cover all anthropogenic greenhouse gases. The planning effort is now in full swing in China, but the pathway to decarbonization is unclear. The needed transition towards non-fossil fuel energy and its impact on China and the world may be more profound than its reform and development over the past 40 years, but the challenges are enormous. Analysis of four representative scenarios shows significant differences in achieving the carbon-neutral goal, particularly the contribution of non-fossil fuel energy sources. The high target values for nuclear, wind, and bioenergy have approached their corresponding resource limitations, with solar energy being the exception, suggesting solar's critical role. We also found that the near-term policies that allow for a gradual transition, followed by more drastic changes after 2030, can eventually reach the carbon-neutral goal and lead to less of a reduction in cumulative emissions, thus inconsistent with the IPCC $1.5^{\circ} \mathrm{C}$ scenario. The challenges and prospects are discussed in the historical context of China's socio-economic reform, globalization, international collaboration, and development.
\end{abstract}

Key words: carbon neutral, carbon dioxide reductions, energy system transformation, distributed energy system, model projections

Citation: Zeng, N., K. J. Jiang, P. F. Han, Z. Hausfather, J. J. Cao, D. Kirk-Davidoff, S. Ali, and S. Zhou, 2022: The Chinese carbon-neutral goal: Challenges and prospects. Adv. Atmos. Sci., 39(8), 1229-1238, https://doi.org/10.1007/s00376021-1313-6.

\section{Article Highlights:}

- The Chinese carbon neutral goal will have profound impact but the challenges are enormous.

- Four representative scenarios show significant differences in how to achieve the carbon-neutral goal, but all agree the importance of solar energy.

- We recommend more aggressive actions on distributed solar, wind, small and modular nuclear, smart grid, and energy storage.

\footnotetext{
$※$ This paper is a contribution to the special issue on Carbon Neutrality: Important Roles of Renewable Energies, Carbon Sinks, NETs, and non- $\mathrm{CO}_{2}$ GHGs.

* Corresponding authors: Ning ZENG, Junji CAO

Emails: zeng@umd.edu, jjcao@mail.iap.ac.cn
}

\section{Introduction}

On 22 September 2020, within the backdrop of the COVID-19 global pandemic, China announced its climate goal for peak carbon dioxide $\left(\mathrm{CO}_{2}\right)$ emissions before 2030 and reach carbon neutrality by 2060 , often referred to as 
"Shuang Tan" or "the two carbon goals" in China $(\mathrm{Xi}$, 2020). After this announcement, President XI has spoken more than 30 times on important occasions and emphasized the importance of the double carbon goal. The planning efforts to reach the two goals are now in full swing in China. This announcement came as a pleasant surprise for the fight against climate change, but the pathway to decarbonization is unclear; the Climate Envoy, Zhenhua XIE, said that the carbon-neutral goal covers all greenhouse gases. The needed transition towards non-fossil fuel energy and its impact on China and the world may be more profound than its reform and development over the past 40 years, but the challenges are enormous.

\section{Roadmap to carbon neutrality}

Currently, China's fossil fuel $\mathrm{CO}_{2}$ emissions are 10.2 Gt $\mathrm{CO}_{2}$ (gigatonnes of $\mathrm{CO}_{2}$ ) in 2019, which compromises $27.9 \%$ of total global emissions (Friedlingstein et al., 2020). In 2020, fossil fuels accounted for $83 \%$ of the total primary energy supply (TPES) with coal representing 57\%, oil 17\%, and gas $9 \%$, while non-fossil fuel accounted for only $17 \%$ (hydro $7 \%$, nuclear $3 \%$, wind $3 \%$, solar $2 \%$, bio $2 \%$ ).

To achieve the carbon-neutral goal, which ambitiously corresponds to not exceeding the $2^{\circ} \mathrm{C}$ target of the Paris Agreement on climate change (IPCC, 2018; Jiang et al., 2018; Project Comprehensive Report Preparation Team, 2020), the ratio of fossil fuel to non-fossil energy sources need to be completely reversed. The low carbon energy system would need to decrease to $80 \%-90 \%$ of the present $\mathrm{CO}_{2}$ emissions [Fig. $\mathrm{S} 1$ in the Electronic Supplementary Material (ESM)]. The remainder (including the non- $\mathrm{CO}_{2}$ emissions) would need to be offset by the terrestrial and ocean sinks and carbon capture, usage and storage (CCUS), resulting in net-zero emissions. We illustrate this with a representative scenario by running the IPAC integrated assessment model (Jiang et al., 2018). We started using the latest Chinese energy and economic statistics of 2020 and then projected them into the future at five-year intervals. The projection shows that, by 2050, the contribution of non-fossil energy would increase to $77 \%$, while the fossil fuel portion would drop to $23 \%$ (Fig. 1 and Table 1). In particular, the contribution of coal would drop below $10 \%$. Additionally, significant carbon sinks and negative emissions will be needed to counter the remaining fossil fuel emissions to achieve netzero $\mathrm{CO}_{2}$ emissions.

While the overall scenario involves detailed modeling of socio-economic and technological development, fossil fuel $\mathrm{CO}_{2}$ emissions can be broadly understood as driven by the following key factors using the Kaya identity (Kaya and Yokoburi, 1997):

$$
\mathrm{CO}_{2}=\frac{\mathrm{CO}_{2}}{\text { Energy }} \times \frac{\text { Energy }}{\mathrm{GDP}} \times \frac{\mathrm{GDP}}{\text { Population }} \times \text { Population },
$$

where $\mathrm{CO}_{2}$ is $\mathrm{CO}_{2}$ emissions from human sources, Energy is energy consumption, and GDP is gross domestic product (GDP).

The past increases in $\mathrm{CO}_{2}$ emissions have been mostly driven by economic development and population increases (Raupach et al., 2007). China's GDP has increased at an average rate of 9\% from 1980-2019 (the 3rd factor in the Kaya Identity above). Going forward, with the annual rate of GDP expected to grow at $4 \%-5 \%$ and the population stabilizing, a complete decoupling of $\mathrm{CO}_{2}$ emissions from GDP growth will be required for the carbon-neutral goal. First, $\mathrm{CO}_{2}$ emission intensity per unit energy generation (the $1 \mathrm{st}$ fac-

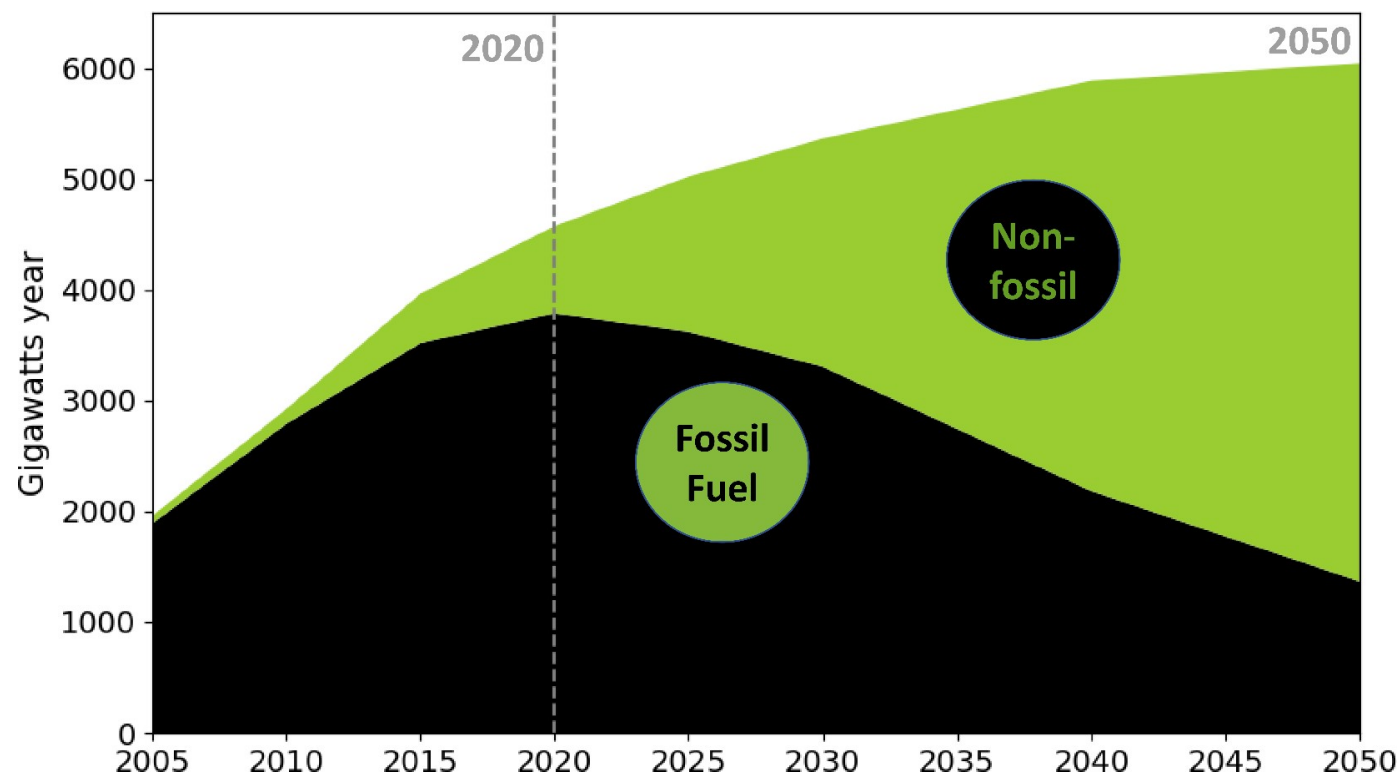

Fig. 1. The Yin and Yang of fossil vs. non-fossil fuel energy source mix. A scenario to achieve China's carbon-neutral goal before 2060 would require a complete reversal of their relative contribution to total energy supply and an unprecedented rapid increase in renewable energy plus nuclear and decrease in fossil fuel use on the timescale of 20-30 years after peak carbon. 
tor) will need to be reduced drastically in a near-complete switch from fossil to non-fossil fuel energy. This can be accomplished by reducing coal and gas on the power generation side and heavy electrification and energy efficiency on the end-user side. Second, decreasing the energy intensity per GDP (the 2nd factor in the Kaya Identity) requires growth to come mostly from the service sector and nonenergy intensive industries such as electronics, which is expected to occur naturally as China's rapid infrastructure build-up over the last 40 years (Zeng et al., 2008) is leveling off.

Regarding power generation specifically, this scenario calls for a 2485 Gigawatts (billion watts or $\mathrm{GW}$ ) of installed solar capacity in 2050, a 9-fold increase from $281 \mathrm{GW}$ in 2020. In the proposed mix, wind power will increase from $244 \mathrm{GW}$ in 2020 to $1508 \mathrm{GW}$ capacity (a 6-fold increase), while nuclear power will increase from $55 \mathrm{GW}$ to $563 \mathrm{GW}$ (a 10-fold increase). Such changes would require an average annual addition of $73 \mathrm{GW}$ of solar-generated power, and 17 GW of nuclear power over the next 30 years, while at the same time reducing coal-fired power by $33 \mathrm{GW}$ per year. In 2050, non-fossil fuel energy sources consisting of nuclear and renewables (solar, wind, hydro, bio) will provide $90 \%$ of the total power generation. After considering the differences in capacity factors, this mix of installed capacities contributes to a total TPES mix of $24 \%$ nuclear and $53 \%$ renewables (Table 1).

\subsection{Different pathways}

To further understand the assumptions and uncertainties, we compared the projections from four $1.5^{\circ} \mathrm{C}$ modeling synthesis scenarios: the IPAC model discussed above,
GCAM-TU (Zhou et al., 2021), and ICCSD (Davidson et al., 2016; Huang et al., 2020; Project Comprehensive Report Preparation Team, 2020), and an ICCSD "transition pathway" (Project Comprehensive Report Preparation Team, 2020) (see ESM). The four scenarios all show a reversal between fossil and non-fossil fuels and similar carbon emissions. However, the energy mix differs significantly.

China submitted the updated Nationally Determined Contributions (NDC) on 28 October 2021 with several new commitments (https://www4.unfccc.int/sites/NDCStaging/ pages/Party.aspx ?party $=\mathrm{CHN}$, accessed on 6 December 2021). China will lower its $\mathrm{CO}_{2}$ emissions per unit of GDP by over 65 percent from 2005 levels. In the Project Comprehensive Report Preparation Team (2020) study, the projected number is $68.2 \%$, a bit higher than the committed lower bound of $65 \%$. For China's goal of non-fossil energy proportion (about $25 \%$ by 2030), the GCAM-TU and IPAC models predicted $36 \%$ and $30 \%$ at 2030 , respectively, in the $1.5^{\circ} \mathrm{C}$ carbon-neutral scenarios (Fig. S2 in the ESM) (Jiang et al., 2018; Zhou et al., 2021). As for the goal of total installed wind and solar power capacity reaching over 1.2 billion kilowatts, the GCAM-TU and IPAC models predicted 1.6 and 1.4 billion kilowatts by 2030, respectively (Jiang et al., 2018; Zhou et al., 2021).

Primary energy projected by the IPAC model increases gradually and plateaus to a level that is $30 \%$ higher in 2050 than in 2020, while the other scenarios only show minor increases (Fig. 2). In 2050, fossil fuel contribution in the ICCSD scenario is $610 \mathrm{GWy}$, only half of the other two, mostly due to a much smaller coal contribution. Non-fossil energy supply ranges from 3630 to $5040 \mathrm{GWy}$, with the

Table 1. Energy sources in the total primary energy supply (TPES) mix. Future years are projected by the carbon-neutral scenario using the IPAC model. Unit is in GWy (Gigawatts year) and percentage of total in parentheses.

\begin{tabular}{cccccccccc}
\hline Year & Total & Coal & Oil & N. Gas & Nuclear & Hydro & Wind & Solar & Bio \\
\hline 2005 & 1956 & $1427(72.9 \%)$ & $404(20.7 \%)$ & $56(2.9 \%)$ & $18(0.9 \%)$ & $45(2.3 \%)$ & $0.8(0.0 \%)$ & $0.0(0.0 \%)$ & $4.6(0.2 \%)$ \\
2020 & 4573 & $2622(57.3 \%)$ & $774(16.9 \%)$ & $390(8.5 \%)$ & $142(3.1 \%)$ & $319(7.0 \%)$ & $145(3.2 \%)$ & $103(2.3 \%)$ & $78(1.7 \%)$ \\
2035 & 5625 & $1641(29.2 \%)$ & $512(9.1 \%)$ & $590(0.5 \%)$ & $818(14.5 \%)$ & $496(8.8 \%)$ & $645(11.5 \%)$ & $501(8.9 \%)$ & $423(7.5 \%)$ \\
2050 & 6044 & $592(9.8 \%)$ & $211(3.5 \%)$ & $563(9.3 \%)$ & $1460(24.2 \%)$ & $535(8.8 \%)$ & $1001(16.6 \%)$ & $982(16.2 \%)$ & $702(11.6 \%)$ \\
\hline
\end{tabular}
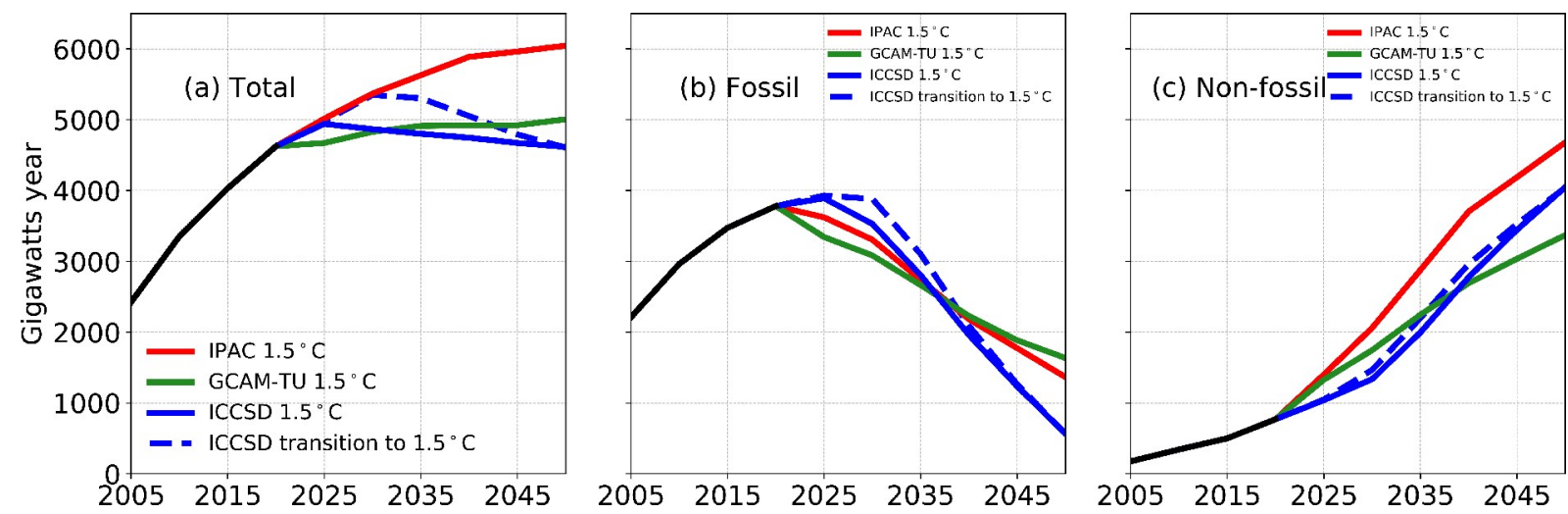

Fig. 2. Energy supply from (a) total, (b) fossil fuel, (c) non-fossil fuel sources from three $1.5^{\circ} \mathrm{C}$ scenarios, and a "transition pathway". 
ICCSD coming in low for all fossil fuels, particularly coal, and the GCAM-TU assumes higher and longer-lasting oil use (Fig. S2 in the ESM).

Large differences exist in non-fossil energy sources (Fig. S2). For example, the IPAC model projects $1570 \mathrm{GWy}$ (or Gigawatts year) nuclear energy, generated by $563 \mathrm{GW}$ of installed capacity, compared to $780-850 \mathrm{GWy}$ in the other two models. The ICCSD scenario projects a much higher contribution from wind energy, $1920 \mathrm{GWy}$, compared to 1010-1080 GWy, for the other two models. The IPAC and ICCSD call for 1040-1060 GWy of solar energy, compared to $430 \mathrm{GWy}$ for the GCAM-TU. Hydropower is the only energy source with good agreement among the models because the development of most of the available resources has already taken place in the last 30 years.

The nearly factor-of-two differences in nuclear, wind, solar, and bioenergy in the 2050 scenarios reflect major uncertainties in the assumptions. For instance, the higher value for nuclear energy in the IPAC model, serving as crucial baseload or firm generation when coal use becomes minimal, requires the use of nearly all of the suitable sites for large-scale nuclear power plants (Jiang et al., 2018; Xiao and Jiang, 2018; Yu et al., 2020). Similarly, the higher contribution from bioenergy implies major competition with food production and other environmental goals (Zhao et al., 2015; Huang et al., 2020), and the higher wind energy scenario in the ICCSD would use much of the technically exploitable resources (Zhang et al., 2011; Yang et al., 2017). In general, the higher target values of most non-fossil fuel energy sources appear to approach resource limitation, with solar energy being the lone exception.

The IPCC $1.5^{\circ} \mathrm{C}$ scenario not only requires long-term commitment but also fast, near-term emissions reductions. However, because of the inertia in the energy system, a pathway is proposed to "transition" from a reinforced-policy scenario to the ICCSD $1.5^{\circ} \mathrm{C}$ scenario (Project Comprehensive Report Preparation Team, 2020). This scenario allows for a gradual transition in the near term, which is more consistent with China's 14th Five Year Plan (FYP) that is currently taking shape (The State Council, 2021) but requires a faster drawdown after 2030 and somewhat different cumulative carbon emissions (Fig. S3 in the ESM). Although it can eventually reach the carbon-neutral goal, this scenario leads to less cumulative emissions reduction, thus inconsistent with the IPCC $1.5^{\circ} \mathrm{C}$ scenario. This adds additional uncertainty to the envisioned pathways, illuminating the scale of the problem and the challenges facing the carbon-neutral goal.

\subsection{Challenges of increasing renewable energy}

Practical solar technology was developed in the US in the 1970s. The 2009 European renewable energy directive spurred its growth as Chinese manufacturers made solar panels that were sold to Germany and other countries. Over the last decade, as the technology further advanced and the scale of the economy expanded, the price of wind and solar power has achieved the stunning feat of price-parity with the Levelized Cost of Electricity (LCOE), which is now cheaper than coal and nuclear (IRENA, 2020; Lazard, 2020). China's installed solar capacity increased from $2.6 \mathrm{GW}$ in 2010 to $43 \mathrm{GW}$ in 2015 and $281 \mathrm{GW}$ in 2020, with an annual addition rate of more than $20 \%$ in the last few years. Even during the 2020 COVID-19 pandemic, $49 \mathrm{GW}$ of solar and $71 \mathrm{GW}$ of wind power were added. The fact that renewable energy is now economically competitive against fossil fuels arguably provides the most important foundation for optimism on the carbon-neutral goal.

However, increasing the contribution to the energy mix of non-fossil fuel from $17 \%$ to $77 \%-85 \%$, a more than 6fold increase, in 30 years will be a daunting task. As the model scenarios show, the higher targets for nuclear, wind, and bioenergy approach their respective resource limits with the notable exception of solar energy. While the available sunlight is not a limitation, it does require vast land, mineral, and other resources. The inherent intermittency of solar and wind power due to diurnal, synoptic weather, and seasonal climate variations gives rise to load balancing and grid security problems, especially when the proportion of this intermittent source exceeds $20 \%$ of the total electricity production. The solution will require technological breakthroughs in energy storage and grid technology. Such a scaling-up investment would need to be at a comparable scale as renewable power generation itself. Such uncertainties and unforeseen costs are not necessarily fully accounted for in the model scenarios or the long-term industry outlook (Global Energy Interconnection Development and Cooperation Organization, 2021).

\subsection{Challenges of fossil fuel and coal phase-out}

To reduce fossil fuel consumption below 15\%-23\% of the total energy by 2050 will be equally challenging. The key to this transition is to impose end-use electrification supplied by renewable energy. China has been aggressively developing electric vehicles, and this market accounts for $50 \%$ of the world's total. Reducing oil use would require electrification of the transportation sector to at least $85 \%$. Electrification of energy-intensive industries such as steelmaking and chemicals is in its infancy. Reducing natural gas use requires the transition of cooking and heating mechanisms from gas to electricity in residential and office buildings, a daunting task in retrofitting an urban infrastructure that is mostly complete. While energy efficiency can improve, other factors may increase demand. For example, traditionally, the Chinese cities south of the Huai River do not use indoor heating, which may eventually change. In the other direction, the demand for cooling will be higher in a warmer world. These factors would require a near doubling of electric power generation, even though the total energy consumption is projected to increase only modestly in the carbon-neutral scenarios.

Nearly $70 \%$ of China's electricity currently comes from coal. Reducing it to less than $10 \%$ in 2050 requires a fast phase-out of existing coal-fired power plants. Is this feasible? As a major baseload, the stability provided by coal will still be critical in the near to medium future. Moreover, China currently has a significant number of coal-fired power plants under construction or approved, although many of these are 
cleaner Integrated Gasification Combined Cycle (IGCC) plants. Given the 30-40 years lifetime of such plants, near elimination of them in 20-30 years implies stranded assets, reduced operation hours and profit, loss of jobs, and other challenges. Recent government policy has been uncertain in coal development, which is not consistent with decisive actions needed for the carbon-neutral goal. A partial remedy during the transition period would be to gradually reduce operation hours as the Chinese coal-fired power plants generally operate at high loads. A rapid coal phase-out will also need to deal with social issues as the coal industry currently employs more than 4 million workers located in a few provinces.

Moreover, the phase-out of fossil fuels, especially coal, also brings the co-benefit of reducing methane $\left(\mathrm{CH}_{4}\right)$ emissions, an important non- $\mathrm{CO}_{2} \mathrm{GHG}$, since energy activity contributed $\sim 50 \%$ of China's anthropogenic $\mathrm{CH}_{4}$ emissions (Lin et al., 2021). Reducing $\mathrm{CH}_{4}$ emissions is assumed to be a cost-effective method of achieving carbon neutrality, especially in the energy sector since methane can be recovered and reused with lower costs than in the agriculture and waste treatment sectors. In the case of $\mathrm{N}_{2} \mathrm{O}$, the reductions would be more difficult than with $\mathrm{CH}_{4}$ since about $60 \%$ of $\mathrm{N}_{2} \mathrm{O}$ emissions are from agriculture (Han et al., 2021). Comprehensive evaluations on promising emission reduction measures are highly needed for both technology, maturity, and cost aspects.

\subsection{Challenges from future uncertainties: nuclear, technological bottlenecks, and geopolitics}

The carbon-neutral goal requires all variables to go in the right direction in a short amount of time: technical, socio-political, and economical. Yet, unexpected events or trends certainly can disrupt the process. Should a coal phaseout shift the lion's share of firm generation to nuclear power, a major nuclear accident becomes a worrisome possibility, despite the excellent safety record of China's nuclear fleet. In the past, society has tended to at least temporarily shift away from nuclear power after a major nuclear accident. For example, the accident at the Fukushima Daiichi nuclear power plant on 11 March 2011 caused serious environmental pollution (Povinec et al., 2013) and public alarm (Huang et al., 2013). For China, it may be prudent to ensure that rigorous safety standards are followed in conventional nuclear deployment while testing safer technology with Small Modular Reactors (SMRs) and advancing better nuclear waste management. Current carbon-neutral pathways rely heavily on conventional nuclear; the extent to which other clean energy sources may play a larger role depends on future technology costs and the extent to which challenges of intermittency and seasonal variations in generation can be solved by breakthroughs in complementary technologies such as grid storage, transmission, and hydrogen production.

With renewables and nuclear dominating the future energy mix, the remaining $15 \%-23 \%$ of energy from fossil fuels still needs to be offset by negative emissions technology. However, it is not clear if the leading candidates, Carbon
Capture and Storage (CCS) in geological formations, Direct Air Capture (DAC), and Bioenergy with CCS (BECCS), will be technologically and commercially successful enough at the needed scale (Fuss et al., 2014; McLaren and Markusson, 2020).

Geopolitical instability remains a major threat to the Paris climate goal. Similar to the large impact of Middle East oil, demand for raw materials can lead to instability and volatility. A hostile relationship among and 'decoupling' of the major world economies will lead to more emphasis on investment in defense, leaving fewer resources for sustainable development and different technological standards that ultimately hinder the spread of renewable technology.

\section{A new energy map}

In 1935, geographer Huan-Yong HU drew a southwestnortheast oriented diagonal line on the map of China, later known as the 'Hu-line' (Fig. 3). He pointed out that $36 \%$ of the land southeast of this line accommodates $96 \%$ of China's population, while to the northwest, $4 \%$ of the population lives on the remaining $64 \%$ of the land. A central geoeconomic reality of China is the separation of China into two regions with distinctly different climates, geography, population, and stages of economic development. This line also separates a fundamental energy "inequality". The semi-arid regions of northwestern China have much of the renewable energy resources as well as fossil fuel reserves that need to be transferred to the industrially developed central and eastern regions of China, except for development along the ancient Silk Road corridor, which is also the main continental connection to central Asia and Europe.

China is developing ultra-high voltage direct current (UHVDC) lines that can run thousands of kilometers, such as the 800 kilovolt, $2193 \mathrm{~km}$-long Baihetan-Zhejiang line currently under construction. However, the current grid system is far from adequate in accommodating a pervasive distributed system at the scale envisioned for carbon neutrality. For instance, assuming $75 \%$ of the $2485 \mathrm{GW}$ solar and $1508 \mathrm{GW}$ wind power projected by the IPAC model for the year 2050 , or $3000 \mathrm{GW}$ combined, needs to be transmitted from the west to the east; such a project would require the equivalent of 300 such UHVDC transmission lines at $10 \mathrm{GW}$ each, with each line occupying large amounts of contiguous land, often over difficult terrain. Yet, this still does not solve the intermittency issues inherent to wind and solar power. Energy storage such as green hydrogen, lithium-ion, solidstate, and other advanced battery technologies at very large scales will be crucial. Still, it is not yet clear they will be available in a timely fashion at a reasonable cost and needed scale.

To realize the renewable-dominated energy map, China will need to develop every possible method in a carefully balanced approach. To minimize the shortcomings of security and reliability of long-distance transmission, distributed energy systems should be widely deployed. While rooftop solar is the poster child of distributed solar, its potential on 


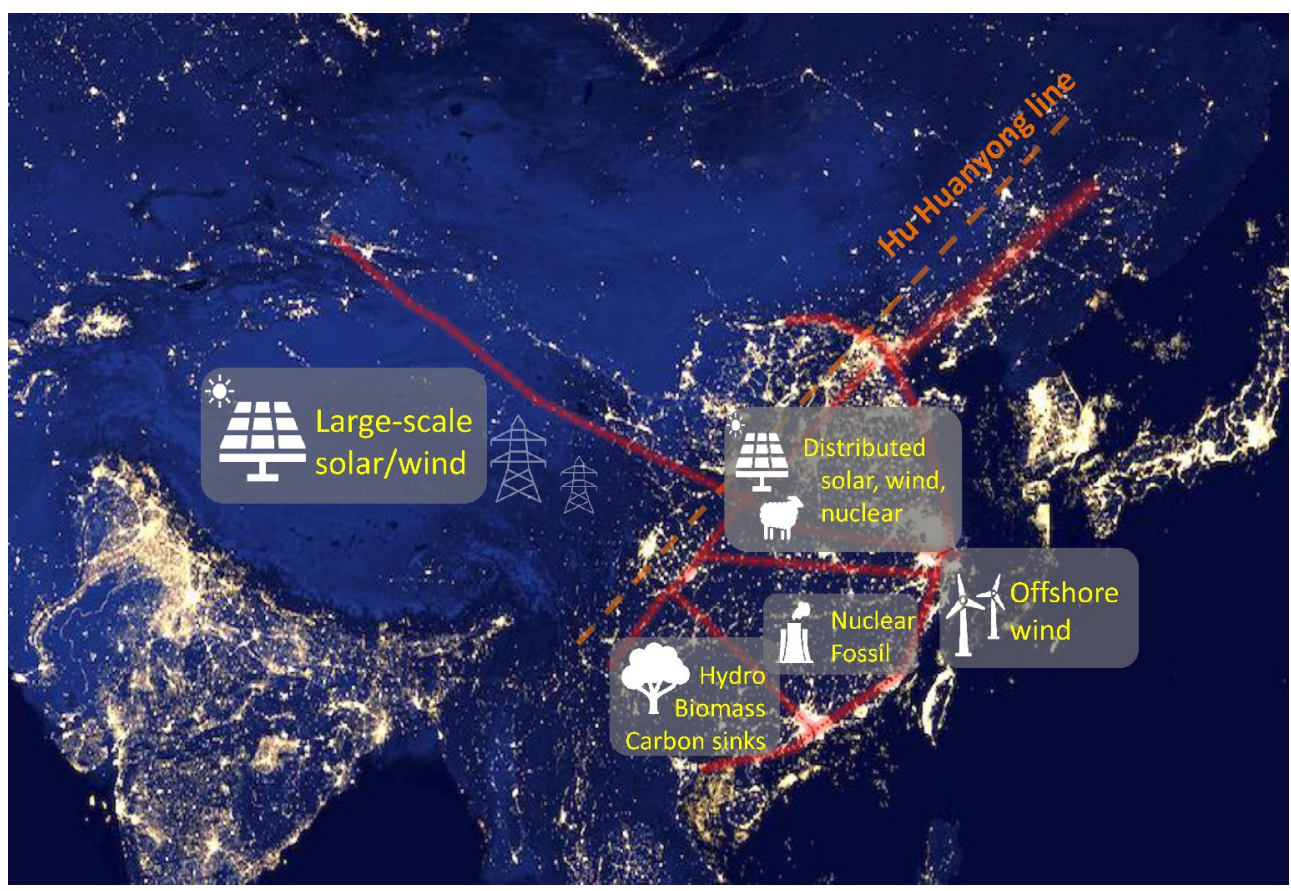

Fig. 3. The new energy map of China with a balanced portfolio. China's carbon-neutral goal would require a stunningly large quantity of interconnected, utility-scale, and distributed non-fossil power generation, as well as carbon sinks that offset remaining fossil fuel emissions.

a per capita basis is limited in Chinese cities where high-rise buildings dominate. In contrast, the potential is much higher in rural regions. Installing solar panels on farmland and grazing land, roadside, hill slopes, and other suitable places in the open countryside (Fig. 4) has the co-benefits of generating power and enhancing plant growth under the panels (BarronGafford et al., 2019), providing green jobs and improving the income of farmers. Currently, China is making particular efforts by providing government-subsidized solar installations for poverty relief at local scales, but there is great potential for a nationwide expansion.

The power from individual solar panels and small wind turbines can be aggregated using micropower stations at the village level. After satisfying local power needs, a large quantity of electricity can be sent from the micro-grid to nearby towns, then to larger cities via the regional and national grids. Such a distributed system goes hand-in-hand with modularized storage systems. Together with electric and hydrogen fuel cell vehicles in the cities, a network of distributed systems with pervasive penetration across the country can catalyze a rapid price drop of energy storage technology, providing a superbly flexible and resilient energy infrastructure.

The current grid system is far from adequate in accommodating a pervasive distributed system at the scale envisioned here. Such a system will require policy and financial incentives. Because the current fossil fuel-based power system already provides a backbone grid, the micro-medium scale systems generally cover the intermediate range of linking houses and farms to the grid. Solar, wind, and small modular nuclear energy and biomass can be similarly integrated into the grid. Such a distributed system and interconnected smart grids will also offer a huge market for the internet of things
(IoT) and related digital technology.

In addition to onshore wind energy, offshore wind energy is another mature technology that can significantly ramp up. This fully renewable energy source has the distinct advantage of being close to the major coastal metropolitan cities such as Tianjin, Shanghai, Shenzhen, Hong Kong, and Guangzhou. Besides building wind farms, careful planning for such a national backbone of coastal transmission cables on land or underwater will facilitate and stimulate offshore wind development (Fig. 3). In contrast to solar, the wind can blow at night and is often stronger in winter than in summer; thus, wind energy has can potentially provide an important buffer for the distributed solar system.

Reforestation and forest protection in China over the last 30 years has contributed to a significant carbon sink, esti-

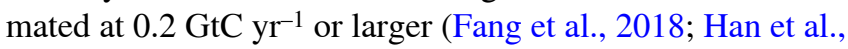
2021). Most of this occurred in southern China, where the climate is wet and warm. However, as these forests mature, their ability to absorb $\mathrm{CO}_{2}$ will decline. Because China is already heavily dependent on agricultural imports, competition for land use will be a major limitation for bioenergy contribution (Zhao et al., 2015; Huang et al., 2020). Novel ways of managing forests to maintain or enhance this sink as negative emissions (Zeng, 2008) may be needed to offset hard-to-replace fossil fuel use.

To achieve the new energy map, it will be critical to strike a balance between adhering to government guidance and stimulating the market economy. In the context of renewable energy development, infrastructure build-up, and the COVID-19 response, the Chinese experience has demonstrated the importance of unified vision, concerted effort, and the willingness to sacrifice some individual interests for 


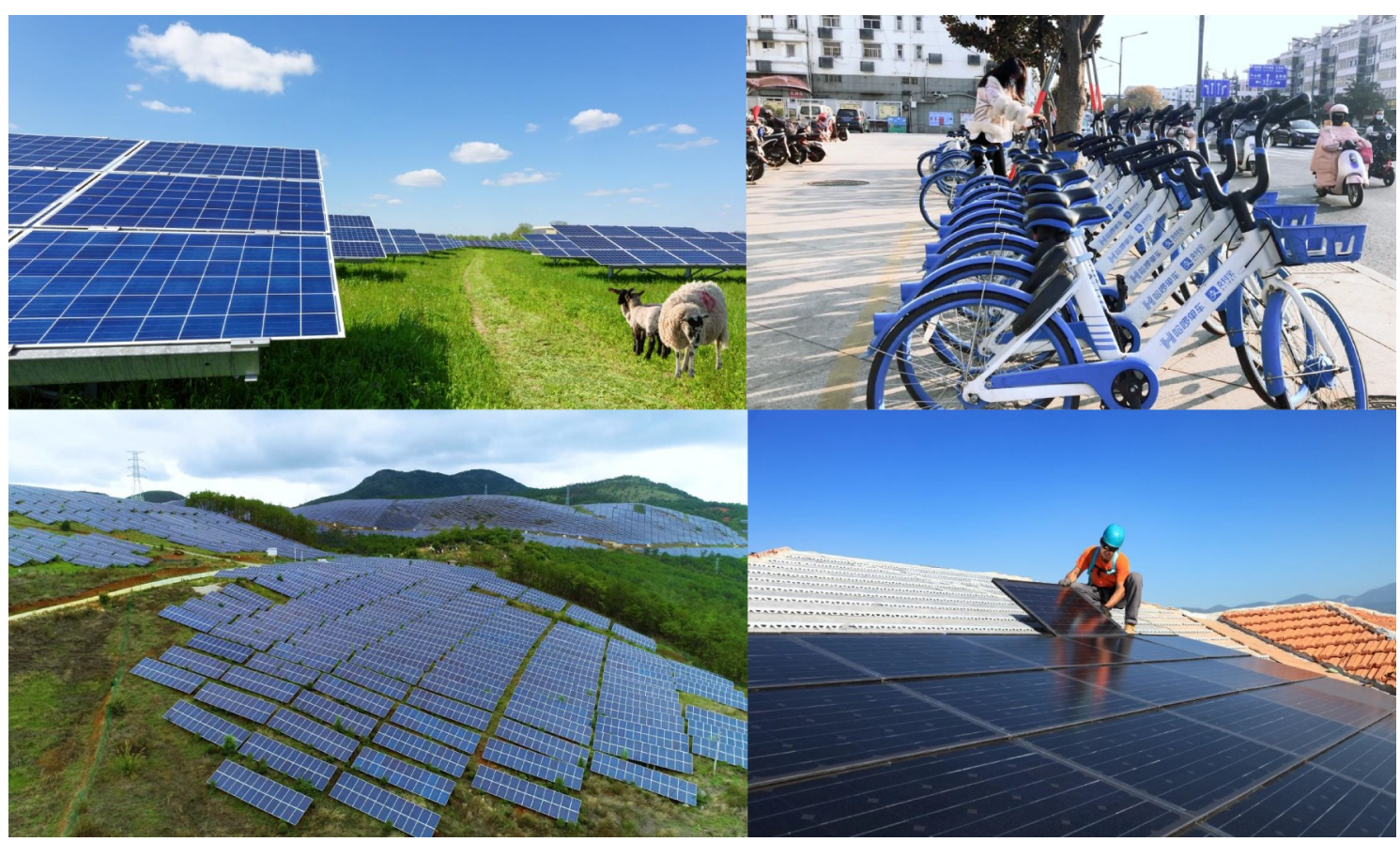

Fig. 4. Top and bottom left: Distributed small solar power systems such as agrivoltaics on a micro-grid with storage embedded in a smart interconnected regional/national grid may be a key to deep decarbonization needed for China's carbon-neutral goal. Top right: end-use efficiency using smart shared bikes to connect the "last kilometer" from home to metro. Bottom right: A worker installs a solar photovoltaic panel on the rooftop of a residential building.

the community when needed. On the other hand, to ensure continued benefits from innovation and the dynamism of the market economy, greater efforts and more careful approaches will be needed both internationally and domestically. For example, the mass production of a distributed solar energy system would require government supports and even mandates for building a suitable national distributed grid that allows electricity generated by the micro solar systems to flow in, while still allowing for market mechanisms for construction and price adjustment.

\section{Research, innovation, and collaboration}

China's GDP has grown at an average rate of $9 \%$ annually over the last 40 years, driven by a national resolve to rise from the "hundred-year turmoil" and a focus on economic development, enabled by the vigor and dedication of 2-3 generations coming from a poverty-stricken background. However, the wealth gap has grown alarmingly large as living standards improve. As China enters a middle-wealth stage, continued development will require a deeper socio-economic transformation. The carbon-neutral goal and sustainable development, in general, provide a big opportunity for this transformation.

China's economic 'miracle' would not have been possible without the scientific knowledge, technology, and management experience in a generous international business and cultural environment. China joined the World Trade Organization (WTO) in 2001, which made the world market accessible, a crucial step leading to substantial improvement in living standards while benefiting the rest of the world. The basic technology of photovoltaics, concentrated solar power, and wind turbines was developed in the US at a commercial scale in the 1970s in response to the Middle East oil crisis. Advancements in high-speed rail have occurred in France, Germany, and Japan and within technology related to lithium-ion batteries in Japan in the 1990s. China has contributed additional developments to these technologies and achieved cost reductions and scale-up.

In the future, China's ambitious carbon-neutral goal will not be possible without continued international collaboration and a conducive international economic and political environment. A key issue is intellectual property (IP) rights. China started its patent and trademark system in 1985, and patent applications accounted for $46 \%$ of the global total in 2018. However, this number does not necessarily reflect the quality of the projects. Technical knowledge has been traditionally regarded with little value, and IP protections are weak. Working closely with other countries to improve IP protections, fair technology transfer, and market access will have the dual benefit of nurturing a productive international relationship and allowing domestic innovation to flourish. Similarly, while China's scientific research output has become number one in terms of the number of papers published, Chinese industry has benefited only modestly from such research. This is not to suggest diminishing research efforts but rather to emphasize establishing and applying multiple criteria for judging scientific output and merit. Research with real and attainable impact should be emphasized, whether basic or applied.

International collaboration sometimes starts unpleasantly and unexpectedly. In 2008, a scientific attaché at the 
US embassy in Beijing set up an air quality monitor on the rooftop and started to post the $\mathrm{PM}_{2.5}$ measurement on the Embassy's website (Kintisch, 2018). The initial reaction from the people of Beijing was to "mind-your-own-business" as the "foggy" weather is painted as natural beauty in traditional Chinese literature and arts. But it did not take long for people to recognize the health threat of air pollution. Now China has a network of thousands of monitoring stations reporting data in real time. Since 2013, the $\mathrm{PM}_{2.5}$ has dropped by $53 \%$ (from $89.5 \mu \mathrm{g} \mathrm{m}^{-3}$ in 2013 to $42 \mu \mathrm{g} \mathrm{m}^{-3}$ in 2019) in Beijing (Beijing Municipal Ecology and Environmental Bureau, 2020). This decrease has been achieved by a combination of factors, including moving heavy polluting industries outside major cities, establishing higher emissions standards, and mandating temporary close-downs of factories during 'bad' weather conditions. While such measures have had significant impact in improving health in highly populated cities during heavy-pollution episodes, the sources of pollution largely remain unmitigated. The carbon-neutral goal provides a great opportunity to deal with air pollution and climate change from their common source-fossil fuel emissions.

The global climate change emergency is an area with high potential for international collaboration. Historically, exchange on climate science through avenues such as the Intergovernmental Panel on Climate Change (IPCC) was instrumental in transforming China from considering climate change an issue invented by the West to playing a leading role today in preventing its further development. Scientists and policymakers should continue to collaborate on the science of climate change and climate mitigation and adaptation strategies. For instance, despite a major investment, much of China's environmental data on the atmosphere and ocean and land ecosystems remain highly fragmented and often not publicly available. A concerted effort from the highest government level to individual research groups will be needed to break bureaucratic obstacles, improve data quality and availability, and create a carbon monitoring and greenhouse gas information system to realize their value for global climate efforts fully.

China's development started with little modern infrastructure so that it has had room for experimentation and competition of different technologies in a "cross-the-river-by-touching-stones" fashion, as phrased by the late Chinese leader Xiaoping DENG. A major drawback of such a trial-anderror approach is the inefficient use of material and human resources and environmental degradation on air, land, and water. For the carbon-neutral goal, China may be able to similarly scale up key technologies such as energy storage, but only with international collaboration, monitoring, and scientific exchange.

\section{International development}

The scale required to deploy solar, wind, and end-use electrification will have major spill-over effects to other countries, thanks to China's ability to scale up and refine a technol- ogy to make it affordable. The potential global impact of a rapid Chinese renewable development may well rival the impact on China itself, not only for its manufacturing capability, but also for the potential for technology development, and spread to developing countries or those soon to be developed where future energy demands are not foreseen.

For instance, in the Belt and Road Initiative (BRI), China plans to spend trillions of dollars in the build-up of infrastructure for developing countries in Asia, Africa, and South America (World Bank, 2018) The construction of coal-fired power plants should be switched to solar and wind farms, specifically fostering the distribution of micro solar power stations for villages and towns and rooftop and farm solar panels for rural households (Fig. 4). Efforts should not be placed solely in constructing solar installations but also directed towards expanding the capacity of human resources. Solar deployment in China will provide green jobs and infrastructure in developing countries, also helping poverty relief. China and India should collaborate because Indian energy demand is rapidly increasing with its large population and fast economic growth. India could become the "next China" in $\mathrm{CO}_{2}$ emissions if it misses the opportunity of renewable deployment in place of coal. Novel approaches such as "debt-for-climate" swaps with developing countries (Simmons et al., 2021) can complement China's carbon goals by more efficient use of resources. Efforts in helping developing countries to sidestep fossil fuel and directly move to renewable energy, especially distributed systems, will make the world better connected and balanced.

\section{Conclusions and expectations}

Achieving carbon neutrality is a broad and profound economic and social systemic change in China. The significance of China's carbon-neutral goal to the Paris climate accord targets and the world's sustainable development and peace cannot be over-emphasized, but the challenges are enormous. Just like China's reform and opening up 40 years ago, China's economic development has brought new surprises to the world. In the same way, with the carbon-neutral vision that started today, China will also meet its carbon-neutral goal 40 years later, bringing confidence and providing a model for other countries in the world. The recently achieved price-parity of solar and wind with fossil fuel energy sources lays the foundation for this ambition; however, deployment at the scales needed is subject to technological and commercial bottlenecks. The envisioned pathways push resource limitations for nuclear, wind, and bio-energy. It is important to research and experiment with all possible technologies. On the deployment side, we recommend a cautious approach with conventional nuclear and a faster phaseout of coal. Still, more aggressive action is needed to distribute solar, wind, small and modular nuclear, smart grid, and energy storage. International collaboration on scientific and technical innovation and deployment will be essential to build a safe, fair, and more resilient common future globally. 
Acknowledgements. This work was supported by the National Key R\&D Program of China (Grant No. 2017YFB0504 000).

Electronic supplementary material: Supplementary material is available in the online version of this article at https://doi.org/ 10.1007/s00376-021-1313-6.

\section{REFERENCES}

Barron-Gafford, G. A., and Coauthors, 2019: Agrivoltaics provide mutual benefits across the food-energy-water nexus in drylands. Nature Sustainability, 2(9), 848-855, https://doi.org/ 10.1038/s41893-019-0364-5.

Beijing Municipal Ecology and Environmental Bureau, 2020. 2019 Beijing Ecology and Environment Statement. Available from http://sthjj.beijing.gov.cn/bjhrb/resource/cms/article/ 1718882/10837172/2020073117581274300.pdf.

Davidson, M. R., D. Zhang, W. M. Xiong, X. L. Zhang, and V. J. Karplus, 2016: Modelling the potential for wind energy integration on China's coal-heavy electricity grid. Nature Energy, 1(7), 16086, https://doi.org/10.1038/nenergy.2016. 86.

Fang, J. Y., G. R. Yu, L. L. Liu, S. J. Hu, and F. S. Chapin III, 2018: Climate change, human impacts, and carbon sequestration in China. Proceedings of the National Academy of Sciences of the United States of America, 115(16), 4015-4020, https://doi.org/10.1073/pnas.1700304115.

Friedlingstein, P., and Coauthors, 2020. Global carbon budget 2020. Earth System Science Data, 12(4), 3269-3340, https:// doi.org/10.5194/essd-12-3269-2020.

Fuss, S., and Coauthors, 2014: Betting on negative emissions. Nature Climate Change, 4(10), 850-853, https://doi.org/10. 1038/nclimate2392.

Global Energy Interconnection Development and Cooperation Organization, 2021. Research Reports on China Achieving Carbon Neutrality Before 2060. Available from https:// www.geidco.org.cn/html/qqnyhlw/zt20210120_1/index.html. (in Chinese)

Han, P., and Coauthors, 2021. Decreasing Emissions and Increasing Sink Capacity to support China in achieving carbon neutrality before 2060. Available from https://arxiv.org/abs/ 2102.10871.

Huang, L., Y. Zhou, Y. T. Han, J. K. Hammitt, J. Bi, and Y. Liu, 2013: Effect of the Fukushima nuclear accident on the risk perception of residents near a nuclear power plant in China. Proceedings of the National Academy of Sciences of the United States of America, 110(49), 19742-19747, https://doi.org/10. 1073/pnas. 1313825110

Huang, X. D., S. Y. Chang, D. Q. Zheng, and X. L. Zhang, 2020: The role of BECCS in deep decarbonization of China's economy: A computable general equilibrium analysis. Energy Economics, 92, 104968, https://doi.org/10.1016/j.eneco.2020. 104968.

IPCC, 2018. Special Report Global Warming of 1.5 degree. Available from https://www.ipcc.ch/sr15/.

IRENA, 2020. Renewable Power Generation Costs in 2019. Available from https://www.irena.org/publications/2020/Jun/ Renewable-Power-Costs-in-2019.

Jiang, K. J., C. M. He, X. Y. Xu, W. Y. Jiang, P. P. Xiang, H. Li, and J. Liu, 2018: Transition scenarios of power generation in China under global $2{ }^{\circ} \mathrm{C}$ and $1.5{ }^{\circ} \mathrm{C}$ targets. Global Energy Interconnection, 1(4), 477-486, https://doi.org/10. 14171/j.2096-5117.gei.2018.04.008.

Kaya, Y., and K. Yokoburi, 1997. Environment, Energy, and Economy: Strategies for Sustainability. United Nations University Press.

Kintisch, E., 2018. Rooftop sensors on U.S. embassies are warning the world about 'crazy bad' air pollution. Science, https://doi. org/10.1126/science.aat9260.

Lazard, 2020. Levelized Cost of Energy, Levelized Cost of Storage, and Levelized Cost of Hydrogen-2020. Available from https://www.lazard.com/perspective/levelized-cost-ofenergy-and-levelized-cost-of-storage-2020/.

Lin, X. H., W. Zhang, M. Crippa, S. S. Peng, P. F. Han, N. Zeng, L. J. Yu, and G. C. Wang, 2021: A comparative study of anthropogenic $\mathrm{CH}_{4}$ emissions over China based on the ensembles of bottom-up inventories. Earth System Science Data, 13(3), 1073-1088, https://doi.org/10.5194/essd-13-10732021.

McLaren, D., and N. Markusson, 2020: The co-evolution of technological promises, modelling, policies and climate change targets. Nature Climate Change, 10(5), 392-397, https://doi. org/10.1038/s41558-020-0740-1.

Project Comprehensive Report Preparation Team, 2020. A comprehensive report on the research of China's long-term low-carbon development strategies and pathways. China Population, Resources and Environment, 30(11), 1-25. (in Chinese)

Povinec, P.P. and coauthors, 2013. Cesium, iodine and tritium in NW Pacific waters - a comparison of the Fukushima impact with global fallout, Biogeosciences, 10(8): 5481-5496. https: //doi.org/10.5194/bg-10-5481-2013.

Raupach, M. R., G. Marland, P. Ciais, C. L. Quéré, J. G. Canadell, G. Klepper, and C. B. Field, 2007. Global and regional drivers of accelerating $\mathrm{CO}_{2}$ emissions. Proceedings of the National Academy of Sciences of the United States of America, 104(24), 10 288-10 293, https://doi.org/10.1073/ pnas.0700609104.

Simmons, B. A., R. Ray, H. B. Yang, and K. P. Gallagher, 2021: China can help solve the debt and environmental crises. Science, 371(6528), 468-470, https://doi.org/10.1126/science. abf4049.

The State Council, 2021. The Outline of 14th Five-year Plan (2021-2025) for National Economic and Social Development and the Long-Range Objectives Through the Year 2035. Available from http://www.gov.cn/xinwen/2021-03/13/ content_5592681.htm. (in Chinese)

World Bank, 2018. Belt and Road Initiative. Available from https: //www.worldbank.org/en/topic/regional-integration/brief/ belt-and-road-initiative.

Xi, J. P., 2020. Xi Delivered an Important Speech During the General Debate of the 75th Session of the United Nations General Assembly. Available from http://www.gov.cn/xinwen/202009/22/content_5546168.htm. (in Chinese)

Xiao, X.-J., and K.-J. Jiang, 2018: China's nuclear power under the global $1.5{ }^{\circ} \mathrm{C}$ target: Preliminary feasibility study and prospects. Advances in Climate Change Research, 9(2), 138-143, https://doi.org/10.1016/j.accre.2018.05.002.

Yang, J. B., Q. Y. Liu, X. Li, and X. D. Cui, 2017: Overview of wind power in China: Status and future. Sustainability, 9(8), 1454, https://doi.org/10.3390/su9081454.

Yu, S., B. Yarlagadda, J. E. Siegel, S. Zhou, and S. Kim, 2020: The role of nuclear in China's energy future: Insights from 
integrated assessment. Energy Policy, 139, 111344, https:// doi.org/10.1016/j.enpol.2020.111344.

Zeng, N., 2008: Carbon sequestration via wood burial. Carbon Balance and Management, 3(1), 1, https://doi.org/10.1186/17500680-3-1.

Zeng, N., Y. H. Ding, J. H. Pan, H. J. Wang, and J. Gregg, 2008: Climate change-the Chinese challenge. Science, 319, 730-731, https://doi.org/10.1126/science.1153368.

Zhang, D., X. L. Zhang, J. K. He, and Q. M. Chai, 2011: Offshore wind energy development in China: Current status and future perspective. Renewable and Sustainable Energy Reviews, 15(9), 4673-4684, https://doi.org/10.1016/j.rser.
2011.07.084.

Zhao, L. L., S. Y. Chang, H. L. Wang, X. L. Zhang, X. M. Ou, B. Y. Wang, and M. R. Wu, 2015: Long-term projections of liquid biofuels in China: Uncertainties and potential benefits. Energy, 83, 37-54, https://doi.org/10.1016/j.energy.2015.01. 060.

Zhou, S., Q. Tong, X. Z. Pan, M. Cao, H. L. Wang, J. Gao, and X. M. Ou, 2021: Research on low-carbon energy transformation of China necessary to achieve the Paris agreement goals: A global perspective. Energy Economics, 95, 105137, https:// doi.org/10.1016/j.eneco.2021.105137. 